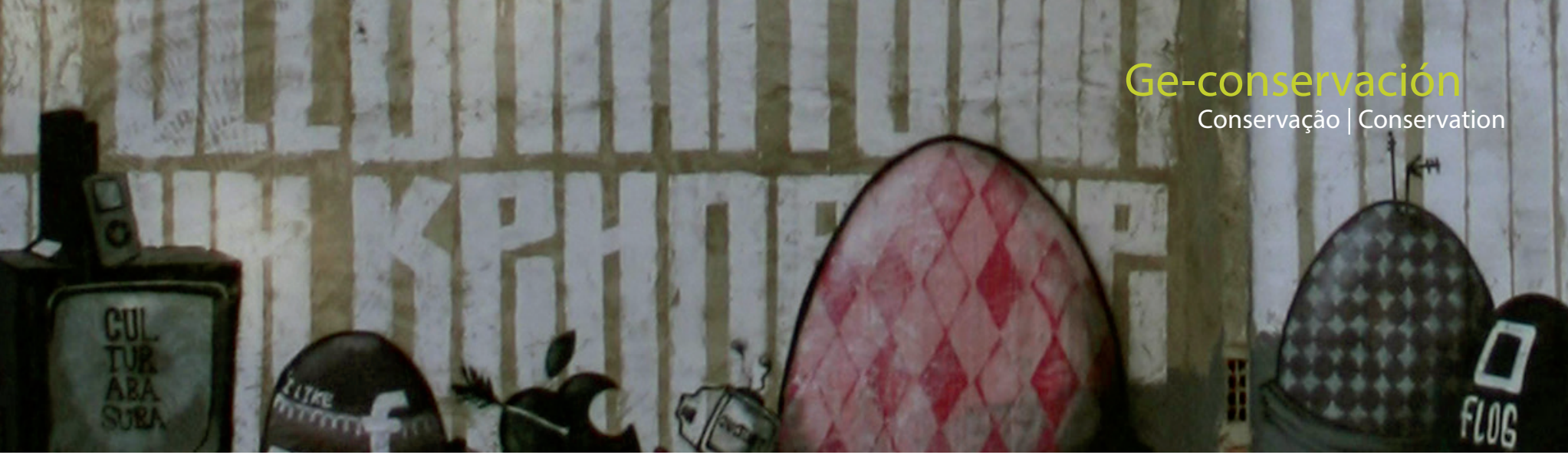

\title{
Arte relacional en la calle. Casos de conservación colectiva
}

\author{
Laura Luque Rodrigo
}

Resumen: Bourriaud formuló en la década de los ‘90 su estética de lo relacional, donde describía la relación entre la obra y el espectador, determinando como el significado es elaborado colectivamente, pero adscribiéndose a obras que específicamente están construidas mediante la participación del espectador. En el siglo XXI este tipo de manifestaciones se han multiplicado en número exponencialmente, sin embargo algunos autores resaltan que los resultados no dejan de ser individuales y contemplativos e incluso que la participación puede producir jerarquías entre las personas. Ante esto, en la actualidad, existen artistas y colectivos dedicados al arte urbano que buscan precisamente crear espacios donde las comunidades sí puedan ser igualitarias, pero ¿cómo se produce la conservación de las obras cuando son colectivas? En este trabajo se analizarán distintos casos mediante entrevistas a artistas y comunidades y documentación.

Palabras clave: Arte relacional, arte urbano, conservación, participación

\section{Relational art in the street. Cases of collective conservation}

Abstract: Bourriaud formulated in the decade of ' 90 his aesthetics of the relational art, where he was describing the relation between the artwork and the spectator, determining as the meaning it is elaborated collectively, but being assigned to works that specifically are constructed by means of the participation of the spectator. In the 21 st century this type of manifestations have multiplied, nevertheless some authors highlight that the results do not stop being individual and contemplative and even that the participation can produce hierarchies between the persons. Before this, at present, there exist artists and groups dedicated to the urban art that seek to create precisely spaces where the communities could be egalitarian, but how does the conservation of the works art take place when they are collective? In this work different cases will be analyzed by interviews to artists and communities and documentation.

Key words: Relational art, urban art, conservation, participation

\section{Introducción}

Desde hace algunos años se han incrementado propuestas artísticas en el ámbito urbano que tienen que ver con lo participativo o colaborativo, confirmando así una tendencia que décadas atrás ya empezaba a perfilarse. Estas propuestas no siempre se desarrollan de la misma forma, en ocasiones parten de los propios artistas, en otras de los vecinos de un barrio o un colectivo concreto y en otras tienen relación con lo institucional. Lo cierto es que no existe una opinión común entre todos, aunque sí se entrevén algunas coincidencias con respecto a la forma de trabajar y de considerar este tipo de arte. Igual sucede con su conservación, la diversidad de opiniones al respecto, a las que hay que sumar también las de los profesionales del sector del patrimonio -historiadores del arte, conservadoresrestauradores, antropólogos, juristas, etc.-, y la falta de consenso y protocolos claros de intervención, provoca la desigualdad en cuanto a las decisiones que se adoptan a la hora de conservar una obra. En este trabajo se presentan algunos casos concretos, sin pretender ser un catálogo completo, en el que se recoge la opinión de algunas de las partes implicadas, con el objetivo de comenzar a establecer criterios comunes, aunque siempre flexibles. 


\section{Arte urbano y participación: breve introducción al arte relacional.}

El situacionismo propuso como eje central la creación de situaciones, es decir, "la construcción concreta de ambientes momentáneos de la vida y su transformación en una calidad pasional superior" (Debord, 1957), con un objetivo político, que cristalizaron en diversas propuestas artísticas durante las décadas de los '70 y ' 80 . Cuando Bourriaud (2008) formuló su estética de lo relacional, en la década de los '90, describió la relación entre la obra y el espectador, determinando cómo el significado es elaborado colectivamente (en consonancia con los planteamientos de Eco para la música y la literatura, pero sobre artes plásticas). El teórico se adscribió en su estudio a obras que específicamente estaban construidas mediante la participación del espectador, conviniendo que "el arte es un estado de encuentro". Así, algunos artistas crean obras donde el objetivo no es la pieza en sí, sino la interrelación con el espectador. Laddaga (2006) destacó la proliferación de obras de carácter participativo o relacionales a partir de 2001, una participación que se define de forma diferente a la que existió en el arte de vanguardia o dentro del arte comprometido, en cuanto se remite a la invención de nuevos modelos de relación y socialización, en contraposición a la producción de masas y la mercantilización del arte, tal y como defendía Bishop (2012: 6-7). Kester (2011), sin embargo, resalta en sus estudios sobre arte colaborativo como, aunque los procesos sean participativos, los resultados no dejan de ser individuales y contemplativos (vídeos, fotografías, etc.). Pero iqué quiere decir participación? Sansi (2014: 24) considera que la participación puede producir jerarquías entre las personas y no sólo comunidades igualitarias. Ante esto, en la actualidad, existen artistas y colectivos que buscan precisamente crear espacios donde las comunidades sí que puedan ser igualitarias, artistas que piden la absoluta participación ciudadana, pues serán los habitantes de los barrios quienes queden como usufructuarios de estas obras de arte público y urbano.

Isidoro Valcárcel (VVAA 2014: 16-17) pone la atención sobre un espectador que no necesariamente tiene que situarse enfrente de la obra, con un cordón en medio: "Ten en cuenta que los receptores no lo son forzosamente como condición y, por otro lado, el emisor (el autor) tiene su obligación a satisfacer, en primera instancia, a su propio criterio y solo en ese segundo lugar al gusto o parecer de los demás". Además de asumir en su definición del arte que es inexorablemente un acto comunicativo y defender la preponderancia del criterio del artista por encima de gustos o modas de mercado, Valcárcel hace algo más. Sobre la afirmación "los receptores no lo son forzosamente", podríamos hacer múltiples interpretaciones, pero si la llevamos al campo que nos ocupa, ipor qué no entender que el receptor pueda participar también del acto de comunicación? Estrella de Diego (2015) considera que frente a otro tipo de propuestas "frías", el arte relacional en un contexto de crisis social como el actual, adquiere una especial importancia. Paul Ardenne indica que el hecho de implicarse en una acción común, modifica la noción de público y revoca el principio de pasividad (Doctor 2013: 161).

Pero, ¿qué abarca el término público? La concepción de público, "implica 'accesibilidad', 'participación', 'inclusión', tener en cuenta a la gente como usuaria del espacio público" (Parcesirsas 2008: 24). Lo que importa es el proceso de creación de la obra y las sinergias que genera en las personas que conforman ese entorno. La obra no nace con la idea de perdurar eternamente y en cualquier caso su trascendencia no depende sino de la propia comunidad que se convierte en usufructuaria.

Sin embargo, existen voces discordantes con respecto al arte urbano, como la de Mario Perniola (2016) que considera que "artificar" el graffiti es dar respuesta a un problema político sobre qué hacer con los jóvenes desempleados de las periferias. Perniola opina que las instituciones crean estructuras que hacen a los jóvenes creerse artistas, esperando que no se amotinen ni caigan en la delincuencia o vandalismo, no obstante, el propio autor afirma que "no existe un mundo del arte sino muchos mundos del arte, que se superponen y se influyen mutuamente".

Muchos artistas, que creen en las posibilidades del trabajo participativo y en la importancia del contexto urbano, consideran que es desde lo local cuando se puede trabajar de forma más directa con las personas y producir esos pequeños micro-cambios en barrios concretos. Es esencial en este punto entender el proceso creativo y formativo para las personas que van a participar y la gestión de la conservación de las obras.

\section{Artistas y proyectos}

"Una obra, sin embargo, es algo que el autor (el auctor: "el que hace") le brinda a los demás para que puedan olvidarse de ella y salgan de esa inmersión con un sentimiento de plenitud y una comprensión distinta a la que el entendimiento procura"

(VVAA 2014: 24).

La ciudad es el espacio en el que se desarrolla la vida pública, especialmente en la plaza, que históricamente ha servido de espacio de reunión y de celebración. Es además ahí, en la plaza, donde con frecuencia se concentran los edificios que representan los poderes, porque adquiere una especial significación. "Por definición el espacio público es aquel que el habitante de la ciudad -habitual o esporádico- puede utilizar sin más limitaciones que ciertas ordenanzas legales y ateniéndose a unas normas de decoro aceptadas 
por el conjunto social" (Fernández 1988: 17-39); tradicionalmente ha estado ligado además a lo masculino, así como la casa a lo femenino, sin embargo, en la actualidad el espacio urbano es tanto del hombre como de la mujer, aunque sigue estando asociado al poder, a la fiesta, al trabajo e incluso, a las reivindicaciones, pues en ellas se desarrollan las manifestación y protestas ciudadanas. En materia artística, la arquitectura ha sido la que tradicionalmente ha estado presente en el espacio público, así como las fuentes y a partir del siglo XIX también el monumento conmemorativo, por ello "la estética urbana ha detectado siempre cada cambio en el medio cultural y lo ha expresado transformando su fisonomía, sustituyendo parte de sus elementos, poblándose de nuevas obras"(Fernández 1988: 17-39). Con la irrupción del graffiti y posteriormente de otros tipos de manifestaciones artísticas urbanas, los artistas comienzan a apropiarse del espacio urbano, con un claro objetivo de realizar obras fuera del mercado y de las instituciones y ligarlas a lo social.

Las manifestaciones artísticas en el espacio urbano convierten "en algo emocionante, excitante y seductor lo que por sí solo no logra manifestarse como tal" (Perniola 2016: 41), aunque con frecuencia estas manifestaciones han sido incluso fuente de conflicto, parece que la integración social del graffiti y la aceptación ciudadana se ha incrementado notablemente en los últimos tiempos, pero esto ha supuesto una institucionalización del arte urbano mediante la creación de concursos, festivales y distinto tipo de convocatorias de las que, al final, el ciudadano queda al margen. La arquitectura, sin duda, es una de las formas más evidentes de construir espacios que generen comunidad, pero también otro tipo de manifestaciones artísticas pueden promover la relación entre las personas, especialmente las prácticas colaborativas, "no siempre desarrolladas en contextos artísticos, cuyos resultados, abiertos e intangibles, pertenecen a los individuos que han formado parte de ella" (Doctor 2013: 202). Pero, ¿participan los ciudadanos verdaderamente de esta situación?

En España existen casos de regeneración de barrios a través del arte urbano y de artistas o colectivos que trabajan sobre la solución de problemas que plantea la ciudad, como el colectivo Truth Behind 404 que busca visualizar de forma crítica y mediante el juego cuestiones sobre la vida en el contexto urbano. Bajo la premisa de que "el arte cambiará el mundo cuando sea parte de la vida cotidiana"1, idean piezas como Make a Sity, con la que pretenden resolver la problemática de la falta de espacios públicos libres en ciudades como Madrid, por lo que crearon un banco que puede ser impreso mediante una impresora 3D y colocado en cualquier punto de la ciudad. El espectador ya no es tal, como indicaba Isidoro Valcárcel, pues debe convertir la idea artística en objeto artístico y ser quien escoja dónde debe estar situado, por lo que habrá tantas piezas como quieran los "espectadores".
El estudio de arquitectura 100 Architects, con sede en Shangai y dirigido por Marcial Jesús (Chile), Madalena de la Venta (Portugal) y Javier González (Chile), realiza intervenciones urbanas con objetos arquitectónicos, tanto efímeros como permanentes, que buscan la interacción y la estimulación de la dinámica social. Aunque no se consideran artistas, sus piezas van más allá de la utilidad, no sólo por la esteticidad o la innovación, sino por lo que generan en las personas. El cambio social por su parte viene de la mano de la sostenibilidad, pues "la escasez de áreas de recreación, el aumento de población mundial habitando en centros urbanos, la falta de tiempo para recreación urbana y la manera en que la revolución tecnológica ha influido e impactado en la forma en que las nuevas generaciones se relacionan con el espacio público", hacen necesaria la irrupción en el contexto urbano de espacios públicos que inviten a interactuar, motiven a crear y generar arte. Sus proyectos de arte urbano son de dos tipos, unos por encargo con vocación de permanencia (que les permita la libertad de emplear materiales holísticos) y otros de carácter efímero autogestionados o relacionados con eventos concretos, que consideran debieran ser rotativos "inyectando vida y dinámicas de cambio a los espacios urbanos"2. 100 Architects, a través de sus proyectos arquitectónicos-artísticos, logran crear espacios relacionales que inciden en las ciudades cambiando sus dinámicas, aunque sea de forma temporal. Los 'espectadores' no participan de la idea ni de la creación en sí de las piezas, pero construyen su significado cuando las usan y las viven, cambiando el concepto de lo arquitectónico, lo urbanístico y promoviendo las relaciones entre los habitantes de las ciudades. Consideramos estas obras como ejemplo de arte relacional aunque no tanto participativo en cuanto a que este término se empleará para definir aquellas propuestas en las que los espectadores participan de forma activa en el proceso de creación.

Existen colectivos que en los últimos tiempos han alcanzado notoriedad como Basurama, quienes con sus autoparques creados a partir de elementos de desecho en zonas deprimidas, implican tanto en su creación como en la posterior conservación a todo un barrio. Formado en 2001 en el seno de la Escuela de Arquitectura de Madrid, sus proyectos tienen un carácter internacional y una gran repercusión social, haciendo reflexionar sobre la enorme acumulación de basura que produce la sociedad de consumo y empleando los desechos como recurso artístico, consiguen generar un beneficio social ${ }^{3}$. Para la creación de los autoparques, espacios de ocio infantil en lugares en desuso, forman a voluntarios que participan en el proceso de creación, generando además un contexto de convivencia y unión colectiva. Uno de estos proyectos, realizado junto a Boa Mistura, en el que han apostado por un arte creado no sólo para los ciudadanos, sino ejecutado por ellos mismos, es el Barrio de San Cristóbal de Madrid. Ambos colectivos artísticos plantearon una serie de intervenciones que pretendían 
cambiar el aspecto de un paso a nivel que resultaba intransitable para los vecinos, mediante la participación de los propios vecinos que convivieron durante unos días entorno a un objetivo común. Lo interesante es no sólo la regeneración del espacio, sino lo que se provoca en las personas, conciencia de barrio y de pertenencia, por otro lado si ponemos la vista en lo meramente artístico, los vecinos realmente tampoco participan de la creación en cuanto a toma de decisiones, simplemente se limitan a hacer tareas del tipo rellenar con color las figuras ya proyectadas.

En el caso de Boa Mistura, colectivo creado también en 2001 en Madrid, buscan en sus proyectos la participación colectiva y se integran en los espacios en los que intervienen de tal forma que alteran su propia concepción artística. Por ejemplo, en Icalupe (Nicaragua, 2015) vieron que las mujeres del pueblo ya pintaban sus paredes recogiendo pigmentos de la tierra que mezclaban con agua por lo que decidieron organizar un taller de temple al huevo para que con los recursos de los que disponen pudieran seguir haciendo sus pinturas, pero de forma más duradera. Es decir, les dieron las herramientas para que ellas pudieran desarrollarse, la experiencia artística en este caso pasa por la formación y la creación juntos de algo identitario y no superpuesto. El arte urbano es la forma para conectar con las personas, el arte tiene capacidad de "estremecer, de inspirar, de emocionar... por eso es tan importante" ${ }^{\prime 4}$ y tiene capacidad para cambiar el mundo.

En algunos casos, sin embargo, como el Soho de Málaga, se pueden dar procesos de gentrificación, pues parten de iniciativas institucionales y no vecinales, sin entrar en aspectos morales, casos como este tienen consecuencias positivas para la ciudad, pero quizá no tanto para los vecinos originarios del barrio que al final terminan marchándose. No es así el caso del Barrio del Oeste de Salamanca, donde la regeneración del espacio a través del arte urbano promovida por la Asociación de Vecinos "Zoes", ha contribuido notablemente a la regeneración del barrio y al aumento del bienestar de sus habitantes. La iniciativa surgió en 2012 con la idea de mejorar el aspecto degradado de un barrio que contaba con el mayor índice de construcción de la ciudad y que contaba con más de quinientas puertas de garaje donde poder intervenir. Desde la Asociación creen que el arte puede contribuir a efectuar cambios sociales, culturales e incluso urbanísticos al generar "sentimiento de permanencia y autoestima colectiva, satisfacción de ser y sentir el Barrio del Oeste, genera adhesión y promoción" ${ }^{\prime \prime}$. Los vecinos participan de la creación y de momentos con los artistas que llegan al barrio de distintas formas (siempre por elección de los propios artistas y cuentan con libertad plena), aportan materiales como escaleras y charlan sobre las obras, además se hacen presentaciones a las que también acuden. En la actualidad, el barrio ha sido incorporado en los itinerarios turísticos de Salamanca.
Dos de los artistas que han participado en el Barrio del Oeste son Pablo S. Herrero y David de la Mano. Éste último considera que los vecinos deben participar de la creación de las obras, "pueden y deberían hacer sus propias propuestas, pero no 'participar' en la creación de piezas realizadas por los artistas", pues aunque puedan ayudar a rellenar, no parece apropiado que actúen como creadores, algo que parece obvio si imaginamos "qué sería de las grandes obras del arte: el Guernica, El Carro de Heno, la Gioconda, Los Girasoles... si se hubieran completado por los niños de un colegio o por los vecinos de un barrio". De la Mano considera que este tipo de obras no pueden considerarse como piezas artísticas, sino otra cosa. Está además convencido de que el arte urbano (y emplea el término con convicción), ayuda a los vecinos a reivindicar la calle, aunque también cree que las ciudades están necesitadas de "curadores y expertos que seleccionen artistas y que ellos lleven a cabo su obra sin condicionantes y con libertad plena"6.

Por su parte, Herrero, que comenzó a pintar en la calle en 2008 después de finalizar la licenciatura en Bellas Artes, cree que el arte puede generar cambios en cuanto a que puede cambiar a las personas y generar conciencia común. Se considera a sí mismo como un 'agente' de un movimiento que cree positivo en su etapa inicial, antes de que se desvirtúe con factores como lo monetario. Desde lo local, en zonas que el propio artista conoce bien, trabaja para mostrar "la ficción de un ecosistema, de un sistema sostenible y dinámico"7. Lo que le mueve a trabajar de forma colaborativa es la comunicación. En relación al Barrio del Oeste, su trabajo consiste en Ilevar a artistas al barrio, y en cuanto a su creación personal, trata de equilibrar el trabajo por encargo con el trabajo por iniciativa propia.

En una línea similar, Sabotaje al Montaje lleva trabajando desde 1990, especialmente en Las Palmas de Gran Canaria y Barcelona. Considera que "el arte tiene que acompañar a la sociedad" y entiende "la calle como un periódico que a diario manifiesta lo que la sociedad actual contempla, por lo tanto puede ayudar a cambiarlo desde su territorio", pues con "el simple hecho de apropiarse de un espacio público ya estamos reivindicando una libertad (y con) el hecho de poner color ya estamos cambiando la sociedad". En los proyectos colaborativos, el artista se convierte en una simple herramienta para el barrio, que les ayuda a crear sus propios "gritos de colores" y a expresar sus propias inquietudes. Sus inicios se enmarcan en el barrio de la Añaza de Tenerife, en los jardines prefabricados, creando murales que los vecinos rellenaban con el color, pero posteriormente decidió que el propio barrio fuera quien tomase sus decisiones artísticas, pues de otra manera las instituciones decidían por ellos sin conocerlos. Lo que buscaba en estos proyectos no era lo pictórico, sino la unión para hacer algo, "no tiene que haber un resultado, solo el proceso, acciones efímeras como la vida, el hecho de que gente tome decisiones en sus espacios ya es un gran paso"8. 
En España, existen precedentes en los que el cambio afecta o a un barrio sino a una localidad completa. Uno de estos casos es el de El Carpio, que a través de Scarpia y de la mano de Miguel Ángel Moreno Carretero, ha conseguido generar no sólo una importantísima colección de arte público situada tanto en el espacio público como natural, sino generar un cambio en la población de la localidad, patente por ejemplo en el incremento de jóvenes que deciden estudiar carreras de ramas artísticas. Otro ejemplo es el de Fanzara, que a través del proyecto M.I.A.U (Museo Inacabado de Arte Urbano), han incidido notablemente en la realidad de una localidad con una población envejecida, convirtiendo cada casa en un lienzo donde crear una obra de arte, lo que ha proporcionado al municipio un atractivo turístico del que carecían, desde hace un par de años.

Aunque el estudio se ha centrado en España, existen experiencias de este tipo reseñables en otros países. Un ejemplo de ello es el distrito de arte en el Windwood de Miami, fundado en 2003 por Mark Coetzee y Nina Arias, generando la aparición de galerías de arte, estudios y espacios alternativos y desde 2007 albergando ferias internacionales, como el ArtBasel. No obstante, este ejemplo parece similar al del Soho de Málaga, un proyecto que ha producido un proceso de regeneración de un barrio histórico, que supone un revulsivo económico, pero que probablemente provoque un proceso de gentrificación si los habitantes originarios no participan de ello. Más integrador parece el proyecto de la Galería de Arte Urbana de Lisboa, que si bien también es una iniciativa institucional, ha propiciado la interrelación entre artistas y ciudadanos con distintos proyectos desde 2008, que no sólo ha servido para situar Lisboa dentro del panorama internacional en cuanto a arte urbano y para incrementar la oferta turística, sino que ha permitido mejorar la imagen de los barrios y lo que nos interesa en este estudio, generar convivencia vecinal a través de algunos proyectos que implican a los vecinos de un barrio, a colegios o particulares en general, como el proyecto BIP-ZIP o Reciclar o Olhar, entre otros. Otro ejemplo interesante tiene lugar en París, en concreto el Distrito 13, pues aquí un especialista escoge varias ideas entre distintos artistas y son los vecinos quienes deciden cuál se lleva a cabo.

El colectivo Wochenklausur, nacido en Viena en 1993, desarrolla propuestas orientadas a reducir las diferencias sociales, siempre desde encargos institucionales. El significado de su nombre "semanas de encierro", indica su método de trabajo, que parte del conocimiento de la realidad en la que van a intervenir. El colectivo realiza obras con el objetivo de impactar en la sociedad, si bien creen que el arte no puede cambiar el mundo, opinan que sí pueden crear mejoras en ciertas realidades sociales. Al no formar parte de los sistemas institucionales o de autoridad, pueden acercarse a los problemas sociales de forma inesperada y sin generar sospechas, lo que facilita el contacto con las comunidades. Sus soluciones deben servir de modelo para solucionar ciertos problemas, inspirándose en modelos del pasado como el Constructivismo Ruso, Joseph Beuys o Artist Placemente Group. Sus obras nacen de conversaciones previas con las comunidades o las organizaciones que trabajan sobre el terreno concreto en que van a intervenir, así identifican cuales son los asuntos que les preocupan y sus deseos, también realizan una investigación sobre la localidad empleando los periódicos locales, internet, etc. No conciben este trabajo como su medio de vida, los miembros del colectivo tienen otros empleos, realizando un par de acciones al año, lo que les permite mayor libertad creativa, a pesar de que siempre trabajan por invitación? 9

\section{La conservación del arte urbano participativo. Análi- sis de experiencias.}

¿QQué sentido tiene restaurar una obra que se autodestruye? -Heinz Althöfer- (...) El acto artístico ya no consiste en fabricar un artefacto que se pueda designar como obra, sino una acción a veces ínfima (...) el papel de la conservación deberá limitarse a documentarlo" (Perniola 2016: 84-85).

La conservación del arte urbano, debe contar en todos los casos con la opinión de sus creadores, pero aún más cuando se trata de arte participativo realizado por y para una comunidad concreta. En un artículo publicado en El País, se preguntó a uno de los vecinos de Fanzara si no temían quedarse sin paredes, a lo que contestó: "pues borramos y comenzamos de nuevo" (Ortega, L. 07/04/2015). Esta afirmación deja claro que en este caso se entiende que las obras no serán perennes en los muros de la localidad, se pretende precisamente el movimiento, que acuda el mayor número de artistas posibles, se busca lo nuevo. ¿Debemos por tanto los profesionales imponer nuestro criterio y conservar algunas de esas obras?

En muchas ocasiones tanto los artistas como los vecinos consideran que las obras deben tener una duración determinada, bien porque la degradación se considera parte de la pieza, bien porque detrás deban venir otras. Pero, en los casos en los que se considere que sí deben tener un mantenimiento que haga la obra más duradera ¿quiénes son los encargados? Sin duda deberían estar en manos de los profesionales, pero es evidente que por cuestiones económicas esto no siempre es posible, en estos casos ¿son los artistas o la comunidad quienes 'reparan' las obras?

En la Asociación de vecino Zoes del Barrio del Oeste de Salamanca, consideran tanto que el arte urbano puede conservarse como que debe ser efímero, pues aunque consideran que detrás de una obra debe venir otra, los 
vecinos "cogen cariño" a lo que llaman los 'lienzos' y pasan a formar parte de este 'museo al aire libre' de forma 'permanente'. En este caso, cuando alguno de los 'lienzos' necesita ser reparado, se recurre al propio artista o si éste está alejado geográficamente, es el propietario del muro o puerta quien lo hace, pero nunca han recibido indicaciones o formación por parte de los creadores para hacerlo.

El objetivo de las intervenciones de Basurama, es "la adquisición de autonomía y el poder de cambio"10 del propio entorno, por ello cuando intervienen en la rehabilitación de un solar o un espacio de la ciudad, es la propia comunidad la que se implica en el mantenimiento, aunque en muchas ocasiones las autoconstrucciones no disponen de los certificados exigidos, por lo que tienen una duración breve.

Boa Mistura se complace al ver como sus trabajos van mutando, creen que son obras vivas que van envejeciendo, como todo en la naturaleza. Consideran que una vez terminan su trabajo la obra es de la comunidad, por lo que deben ser ellos mismos quienes la cuiden y respeten ${ }^{11}$, por ello dejan algunas indicaciones en las comunidades en las que intervienen. Por ejemplo, en el proyecto Bacatá (Bogotá), dejaron un dossier en el que no sólo se explica y justifica el proyecto, sino que además se incluyen esquemas con el diseño, los colores, significación, proceso de trabajo, materiales, descripción técnica, y unas recomendaciones de mantenimiento. Éstas, no obstante, son muy nimias, se limitan a indicar que no se laven con agua y jabón durante los primeros treinta días después de su aplicación y que en caso de restauración cuentan con la información necesaria en el informe, pero obviamente esta restauración para ser tal debería realizarla un profesional, pues los ciudadanos sólo podrían limitarse a rellenar con color las zonas afectadas, de forma más o menos acertada, por lo que deberían considerarse repintes. Ellos mismos participaron en la restauración del mural "Somos Luz" en São Paolo, gracias a la colaboración de Odebrecht y Luz Botero y con la participación de los propios vecinos. Es decir, Boa Mistura diferencia entre las obras que hacen por iniciativa propia, las que prefieren ver evolucionar hasta morir; las que realizan para una comunidad, que deben conservar los propios vecinos y las encargadas por una institución. En cuanto a su técnica, difiere en cada proyecto, en el caso de Bacatá, se empleó pintura fabricada a partir de copolímeros diluibles en agua (pintura vinilacrílica).

David de la Mano, en cambio, no está de acuerdo con la conservación del arte urbano, de hecho considera que "una de las grandes virtudes del arte urbano" es precisamente el envejecimiento, el paso del tiempo que debe vivirse con naturalidad, aunque sí considera apropiado el registro fotográfico. También Sabotaje al Montaje cree que el arte urbano debe ser 'efímero', pues nuestra sociedad cambia muy rápidamente y el arte debe ir en paralelo, solo la memoria debe ser la conservación. Por ello, no hace seguimiento de las obras, aunque sí suele dar unas pequeñas clases formativas a las personas que van a colaborar en sus trabajos colaborativos, pero cree que cuando realmente aprenden es trabajando de la mano con el artista. Los productos empleados por Sabotaje al Montaje también difieren en cada proyecto, pero generalmente usa spray, pintura plástica y materiales reciclados.

Pablo S. Herrero, tampoco está de acuerdo con la conservación, especialmente si son obras espontáneas y en todo caso piensa que el artista debe ser consultado previamente y que la restauración "no debe responder a intereses relacionados con la especulación con bienes raíces, debe atender a lo que la comunidad demande". Por ello, aunque al inicio sí hacía seguimiento de las obras, dejó de hacerlo, a pesar de que en ocasiones le llegan fotografías de algunos de sus murales en los que puede comprobar su evolución, pues realmente lo que al artista le gustaría es que la naturaleza cubriera la 'ficción' que pintó. También Herrero emplea generalmente pintura plástica, y si el soporte está muy degradado los prepara previamente. Cuando el trabajo es remunerado además emplea un fijativo.

El colectivo Wochenklausur tampoco hace un seguimiento de las obras, sólo al inicio de haberlas creado y opinan que la intención con la que se crea la obra es la que debe determinar si la pieza debe perdurar en el tiempo o ser efímera. El colectivo, en concreto apunta a proyectos sostenibles que perduren a largo plazo. En ocasiones dejan obras terminadas, pero en otras lo que crean son estructuras que deben ser continuadas por la comunidad, siempre y cuando hayan podido asegurar previamente apoyo financiero e implicar no sólo a la comunidad sino a profesionales o personas con formación. Aun así, piensan que la auténtica conservación parte de la documentación, que reconocen no siempre realizan de forma completa.

Parece evidente que los artistas consideran esencial el proceso de documentación de las obras como parte, en muchas ocasiones única, de la conservación de las obras. David de la Mano incluso indica que "las ciudades están más necesitadas que nunca de curadores y expertos que seleccionen artistas y que ellos lleven a cabo su obra sin condicionantes y con una libertad plena". Reproducimos el término 'curador' empleado por el propio artista, aunque no estamos de acuerdo con la españolización del término inglés por ser impreciso y poco correcto, se recomienda el uso de 'gestor cultural' o 'comisario de exposición'. Las palabras del artista hacen patente la falta de un sistema que permita tanto a los artistas como a los expertos y comunidades, llevar un registro completo de las creaciones que se están llevando a cabo en la calle. 


\section{Conclusiones}

Son varias las reflexiones que podemos extraer a raíz de conocer estos ejemplos de creación y conservación participativa, especialmente a partir de las opiniones de los propios artistas. En primer lugar, nos planteamos si en el caso de aquellas comunidades que se encargan de la propia rehabilitación del barrio, en este caso mediante iniciativas artísticas, no están ejerciendo una función que realmente debería corresponder a las instituciones pertinentes. No quiere decir esto que los vecinos pierdan el contacto con sus barrios, al contrario, las instituciones tienen una tarea pendiente al respecto, pues el trabajo en las ciudades debería ser mucho más cercano a sus habitantes y por lo tanto las actuaciones que se acometiese estarían vinculadas a los deseos y a las decisiones que tomasen las mismas comunidades. Es evidente que las propuestas más interesantes parten de los propios vecinos en muchos casos, no se trata pues de terminar con esa iniciativa, sino de que las instituciones no deleguen sus funciones. Por otra parte, cuando se trata de un movimiento vecinal, nos planteamos hasta qué punto la libertad de los artistas es plena a la hora de crear. En los casos analizados es obvio que existe tal autonomía creativa, aunque por ejemplo en el Distrito 13 de París, son los vecinos quienes eligen la propuesta que más les interesa. ¿Tienen los ciudadanos conocimientos y criterio para tomar decisiones de tal calibre? Lo cierto es que son ellos quienes van a convivir con las obras y en ocasiones se producen enfrentamientos innecesarios, como en el caso del graffiti de la rata en el Soho de Málaga, que tanto horrorizó a los vecinos de la zona. Pero, ¿no son necesarios en ciertos casos estos choques para remover algo en las personas, generar una reflexión o incluso una crítica? Podría ser el reciente caso del mural de Borondo en Berlín en el que se representa a una niña refugiada ensangrentada. Evidentemente a los vecinos no les agrada una visión tan real y de actualidad, pero probablemente sea necesario para despertar conciencias.

En este punto es donde entra el importantísimo papel del experto en la materia y es que tal y como apuntaba David de la Mano, las ciudades están necesitadas de la presencia de más profesionales de la cultura trabajando para ella. Debemos pensar que el criterio de un grupo de personas que se dedican al arte debe ser no sólo tenido en cuenta, sino que ha de ser el instrumento de trabajo que genere ciudad y establezca los criterios artísticos, aunque tampoco podemos presuponer que este criterio sea siempre acertado e infalible, por ello no proponemos que su opinión prevalezca como única e indiscutible, sino que sea el nexo de unión entre instituciones, artistas y comunidades, para llegar así a un equilibrio perfecto. Probablemente un buen ejemplo de ello sea el caso de Lisboa, donde el Ayuntamiento genera este diálogo y potencia la creación de forma que todos los sectores estén conformes.
Nos referimos siempre en este punto a obras realizadas por encargo en la ciudad, ya sea por iniciativa pública o privada, en ningún caso nos referimos a obras espontáneas de los artistas. Además ellos mismos diferencian muy bien entre los distintos tipos de obras que realizan. Cuando son encargos entienden, en el aspecto de la conservación, que al ser remuneradas los materiales empleados deben ser lo más duraderos posible; cuando son colectivas consideran que las comunidades tienen mucho que decir al respecto y que la obra deja de ser del propio artista para ser de la comunidad en cuanto está terminada; en cambio, cuando son obras espontáneas, generalmente gustan de ver su evolución que conlleva la degradación y desaparición al cabo del tiempo.

En resumen, es evidente que artistas y comunidades van por delante de las instituciones e incluso de los profesionales, que estos últimos deberían tener mucha más presencia en las ciudades, que existe una enorme necesidad de consenso entre las partes y que es necesario aportar un protocolo que permita a todas las partes implicadas documentar los procesos artísticos que se están dando en la calle de forma que la memoria no se pierda, que se promuevan los estudios académicos al respecto y el conocimiento por parte de cualquier persona interesada. Un trabajo desarrollado al respecto fue presentado en el 5th INTERNATIONAL CONFERENCE YOuth in COnservation of CUltural Heritage, 2016 por Carmen Moral Ruiz y quien escribe este trabajo, el 21 de septiembre de 2016.

\section{Notas}

[1] TRUTHBEHIND 404 (Correo electrónico, 19 de enero de 2015).

[2] 100 Architects (Correo electrónico, 15 de junio de 2016)

[3] BASURAMA (Correo electrónico, 3 de noviembre de 2014).

[4] BOA MISTURA (Correo electrónico, 30 de junio de 2014 y 16 de octubre de 2014). Grupo artístico.

[5] Asociación de Vecinos Zoes (Correo electrónico, 7 de junio de 2016)

[6] David de la Mano (Facebook, 7 de junio de 2016)

[7] Pablo S. Herrero (Correo electrónico, 8 de junio de 2016)

[8] Sabotaje al Montaje (Correo electrónico, 21 de junio de 2016)

[9] Wochenklausur (Correo electrónico, 8 de junio de 2016)

[10] BASURAMA (Correo electrónico, 3 de noviembre de 2014).

[11] BOA MISTURA (Correo electrónico 16 de octubre de 2014). 


\section{Bibliografía}

BISHOP, C. (2004). "Antagonism and relational aesthetics", October magazine, 110: 51-80.

BOA MISTURA. Tedx Madrid. 9 de octubre de 2012. Consultado el 10 de febrero de 2015. https://www.youtube.com/ watch?v=gKRNLXghU94\#t=431

BOURRIAUD, N (2008). Estética relacional. Córdoba (Argentina): Adriana Hidalgo Editora.

DE DIEGO, E (2015). Artes visuales en occidente desde la segunda mitad del siglo XX. Madrid: Cátedra.

DEBORD, G. (1957). Informe sobre la construcción de situaciones y sobre las condiciones de la organización y la acción de la tendencia situacionista internacional. Documento Fundacional.

DOCTOR RONCERO, Rafael (coord.) (2013). Arte español contemporáneo, 1992-2013. Madrid: La Fábrica.

FERNÁNDEZ ARENAS, J. (1988). Arte efímero y espacio estético. Barcelona: Anthropos.

GRANT, K. (2011). The one contemporany art and the many in a global context. Durham: Duke University Press.

LADDAGA, R. (2006). Estética de la emergencia. Buenos Aires: Adriana Hidalgo Editora.

ORTEGA, L. "Fanzara, capital del grafiti", El País [7 de abril de 2015], s.p.

PARCERISAS, P. (2008). “Arte y contexto. Hacia una redefinición del espacio público y el arte político", Arte, experiencias y territorios en proceso. A. de Calaf, A. de Manresa, Generalitat de Catalunya, Diputació Barcelona: 24-36.

PERNIOLA, M. (2016). El arte expandido. Madrid: Casimiro.

QUIROSA GARCÍA, V.; LUQUE RODRIGO, L. (2015). "Arte útil para la sociedad. Consideraciones entorno a seis artistas del siglo XXI en España", De arte: revista de historia del arte, 14. León: 249-261.

SANSI, R. (2014). "Arte, don y participación", Ankulegi, 18. Asociación Vasca de Antropología: 13-28.

VALERO, C. "Polémica en Berlín por un mural de una niña refugiada ensangrentada", El Mundo [22-06-2016], s.p.

VVAA. (2014). Cartas a Jóvenes artistas. Madrid: Continta me tienes.

"Los vecinos opinan sobre el grafiti de ratas del plan del Soho", El Observador [18/07/2013], s.p. (https://goo.gl/ teMqnX)

\section{Referencias Web}

Web oficial de Scarpia, http://scarpia.es/2015/ [consulta: 22/07/2016].

Web oficial de FAR (Foro de Arte Relacional), http://www. foroarterelacional.com/ [consulta: 22/07/2016].

Web oficial de 100 Architects, http://100architects.com/ [consulta: 22/07/2016].

Web oficial de Sabotaje al Montaje, http://www. sabotajealmontaje.com/ [consulta: 22/07/2016].

Blog oficial de David de la Mano, http://daviddelamano. blogspot.com.es/ [consulta: 22/07/2016].

Blog oficial de Pablo Herrero http://lasogaalcielo.blogspot. com.es/ [consulta: 22/07/2016].

Web oficial del Distrito del Arte de Miamia, http://espanol. miamiandbeaches.com/places-to-see/design-district [consulta: 22/07/2016].

Web oficial de Wochenklausur, http://www.wochenklausur.at/ [consulta: 22/07/2016].

Web oficial de la Asociación de Vecinos ZOES, Barrio del Oeste de Salamanca, https://zoes.es/ [consulta: 22/07/2016].

Web oficial de de Miau, http://miau32.wixsite.com/ miaufanzara [consulta: 22/07/2016].

Web oficial de Basurama, http://basurama.org/ [consulta: 22/07/2016]

Web oficial de Truth Behind 404, http://www.truthbehind404 com/ [consulta: 22/07/2016].

Web oficial de de Boa Mistura, http://www.boamistura.com [consulta: 22/07/2016].

Blog oficial de Miguel Ángel Moreno Carretero, http:// miguelangelmorenocarretero.blogspot.com.es/ [consulta: 22/07/2016].

Perfil en ISSU de la Galería de Arte Urbana de Lisboa, https:// issuu.com/galeriadearteurbana [consulta: 22/07/2016]. 


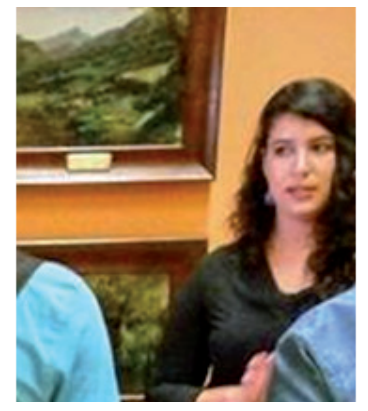

\section{Laura Luque Rodrigo}

Universidad de Jaén

lluque@ujaen.es

Doctora en Historia del Arte por la Universidad de Jaén, trabaja como profesora sustituta interina en el Área de Historia del Arte de la misma universidad. Sus investigaciones siguen dos líneas, por un lado en relación a su tesis Doctoral “Los Palacios Episcopales en Andalucía Oriental. Lecturas de Significación", sobre arquitectura de la Edad Moderna y Contemporánea y por otro, ha desarrollado otra línea vinculada al arte contemporáneo y últimamente al arte urbano. Ha trabajado en los inventarios de bienes muebles de la Catedral de Jaén, la Diputación Provincial y la Universidad de la misma ciudad. Ha participado en casi una treintena de congresos nacionales e internacionales, publicado numerosos artículos, capítulos de libro y libros. Ha participado en diversos proyectos de investigación relacionados con el arte contemporáneo y en un proyecto de innovación docente. Además ha coordinado más de veinte actividades de difusión, la mayoría relacionadas con el arte contemporáneo, entre las que se encuentra la Noche en Blanco de Jaén en sus primeras dos ediciones, Scarpia 365 y FAR. Pertenece al grupo de investigación Arquitecto Vandelvira (HUM 573) y es miembro del comité científico de la revista Galería Abierta. 